\title{
On the Influence of Inorganic Salts upon the Conidia-formation of Aspergillus niger.
}

\author{
(Preliminary Note.)
}

By

Atsushi Yasuda, Rigaliushi.

To our knowledge of the influence of changed external conditions upon various kinds of moulds many interesting contributions have hitherto been made. Recently, the investigations towards this branch of physiology seem to be of especial abundance. Eschenhagen ${ }^{1}$ ) has studied the effects of cane-sugar, glycerine, sodium and potassium nitrates and sodium and calcium chlorides on Aspergillus niger, Penicillium glaucum and Botrytis cinerea. Schos'akowirsch ${ }^{2}$ ) has investigated the conditions wanted to the conidiaformation of Fumago, Hormodendron, Dematium \&c. He has also given in another paper $^{3}$ ) the like about Mucor proliferus. The fact that heterogeneous forms of Thamnidium elegans depended on the chemical nature of substrata, their degrees of concentration, liquidity, moisture and temperature has been demonstrated by the experiments of BaCHMANN ${ }^{4}$ ), and also that varions modes of growth of Basidiobolus ranarum were influenced by the characters of liquid-media has been noticed by Racmonski $1^{5}$ ).

KLEBS gave in his great work ${ }^{6}$ ) detailed accounts concerning the formation of the reproductive organs of Eurotium repens and Mucor racemosus.

2) F. Escheninagren. Ueber den Einfluss von Lösungen versehiedener Concentration anf das Wachsthum von Schimmelpilzen. Stolp 1889. S. 10.

2) W. Schostakowitschr. Ueber die Pedingungen der Conidienbildung bei Russthanpilzen. Flora. 1895. Bd. LXXXI. S. 362-393.

3) W. Schostakowitsch. Einige Versuche über die Abhängigkeit des Mncor proliferus von den äusseren Bedingungen. Flora. 1897. S. 88-96.

4) J. Bachmann. Einfluss der äusseren Bedingungen auf die Sporenbildung von Thamnidium elegans Link. Bot. Ztg. 1895. Abt. I. S. 129-130.

$\left.{ }^{5}\right)$ M. RAcibonskr. Ueber den Einfluss äusserer Bedingungen auf die Wachsthumsweise des Basidiobolus ranarum. Flora. 1896. Bd. LXXXII. S. 110-121.

$\left.{ }^{\circ}\right)$ G. KLEbs. Die Bedingungen der Fortpflanzung bei einigen Algen und Pilzen. Jena 1896. S. 446-532. 
More recently he made an investigation of Sporodinia grandis ${ }^{1}$ ), and came to the conclusion, that by changing the nature of substrata one or other kind of sexual organs was artificially produced according to the author's will. Further, ILNDNER ${ }^{2}$ ) studied Mucoreae with reference to light and sulstratum. Ra ${ }^{3}$ ) observerl that Sterigmatocystis alba produced only pencils of unbranched sterigmata instead of ordinary branched ones, when it was sown in a sugar-solution, while that cultivated in a salt-solution showed merely sterile conidia-bearing hyphae.

For my part I have examined by a series of experiments how the conidia-formation of Aspergillus niger is influenced by chemical nature and concentration-grade of various inorganic salts. The greater part of this work has not yet been completed, so that I will here give some of the results as only a preliminary note.

To begin with, I prepared a liquid-medium, which afforded to my fungus an abundant nourishment and the most complete development. I used it as a fundamental medium throughout my experiments, adding to it every time certain quantities of inorganic salts. For the medium in question I preferred the solution proposed by Prof. Mryoshi ${ }^{4}$ ). For conrenience sake, I will here give its composition :

Distilled water...................................50 c cm

Concentrated boiled solution of Allium-bulbs........25 ,

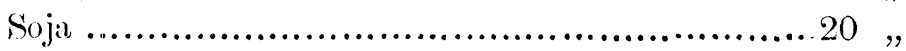

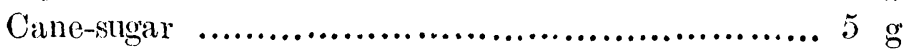

The inorganic salts which I used for my experiments were those of potassium, sodium, ammonium and magnesium. On the examination of my cultures I always compared them with the control-culture, which I made, simultaneously with the other cultures. During the experiments my attention was especially turned to the development period of conidia-bearing hyphae as well as to the coloming period of conidia. I also observed the length of conidia-bearing hyphae, the thickness of their cell-walls, the size of conidia-fruits and the diameter of conidia themselves. As a matter of fact the development of mycelium and reproductive organs is greatly in-

1) G. Kuciss. Znr Physiologie der Fortpflanzing einiger Pilze. Jahrb. f. wiss. Bot. 1898. Pd. XXXII, Heft 1. S. 41.

${ }^{2}$ ) A. Lendener. Des influences combiées de la lumière et du substratum sur la développement des Champignons. Ann. d. Sc. nat. Bot. 1897. Sér. VIII, T. 3. p. 1-64.

3) J. RAY. Variations des champignons inférieurs sons l'inflnence du milieu. Revue générale de Botanique. 1897. T. 9. p. 301.

4) M. Mrosur. Durchbohrung der Membranen durch Pilafïden. Jahrb. f. wiss. Bot. 1895. Bd. XXVIII, IIeft 2. S. 272. 
fluenced by temperature, and during my experiments the room-temperatire was found to lie between $17^{\circ}$ and $22^{\circ} \mathrm{C}$.

Now I will make some remarks on each culture, showing the results of my experiments.

\section{Potassium salts.}

The salts which I chose to experiment with were chloride, bromide, iodide, nitrate and sulphate.

Control-culture. - On the 7th day after sowing the spores white conidia-fruits were formerl. On the 9th they coloured yellow, which changed into dirty brown on the 14th. The average length of conidia-bearing hyphae was $3 \mathrm{~mm}$, their diameter $18 \mu$ and the thickness of their welldeveloped cell-wall $3 \%$ Ripened conidia-fruits $0.5 \mathrm{~mm}$ in diameter, spores $5 \mu$.

a. Potassium chloride.-A $5 \%$-culture formed white conidia on the 7th day after inoculation, which became black on the 9th. This early blackening of conidia distinguished it clearly from the control-culture. Moreover the conidia-fruits increased in size, while the conidia-bearing hyphae somewhat decreased in length. A $10 \%$-culture produced white conidia on the 9th day, which blackened after two weeks. 'The particulars of this culture were nearly the same as the former in all respects. A $15 \%$ culture, however, caused not only a remarkable change of reproductive organs but also a retardation of their development. Thus the conidia-fruits from this culture measured $0.18 \mathrm{~mm}$ in diameter and the conidia-bearing hyphae $0.85 \mathrm{~mm}$ in length and $13 \%$ in breadth, a great diminution as compared with those of the normal culture; the appearance of white conidia-fruits was delayed till the end of the 24th day, and on the 31st they were observed to blacken.

b. Potassium bromide.-A $5 \%$-culture formed white conidia on the 8th day, which changed into dirty brown on the 10th. Compared with the control-culture no distinct change could be scen. A $10 \%$-culture produced white conidia-fruits on the 10th day, which in the course of two days more became brown and black. On the 12 th day a $15 \%$-culture presented the first step of conidia-formation. On the 17th the conidia became brown and black. In this culture the conidia fruits as well as the conidia-bearing hyphae decreased in size-the former $0.36 \mathrm{~mm}$ wide, the latter $1 \mathrm{~mm}$ long and $12 \mu$ thick. A $20 \%$-culture showed the conidiaformation first on the 15th day.

c. Polassinm iodide.-A 5\%-culture was characterized by a slow 
development of conidia-fruits and a long extension of conidia-bearing hyphac. Thus it produced white conidia-fruits on the 12th day, which coloured dirty brown on the 25 th ; the length of conidia-bearing hyphae gave $4 \mathrm{~mm}$. The diameters of conidia-fruits varied from 0.15 to $0.7 \mathrm{~mm}$. A $10 \%$-culture formed white conidia on the 16th day, which changed to dirty brown on the 27th. Conidia-fruits were long-stalked and rather scatteringly developed. They were small in general, but mixed with some large ones, their diameters varying $0.25-0.57 \mathrm{~mm}$. In a $15 \%$-culture white conidia-fruits first appeared on the 18th day and ripened on the 34th. The formation of conidiabearing hyphae was very much reduced, showing only a scanty local development, so that the greater part of the mycelium remained entirely naked. T'he size of conidia-fruits themselves diminished beyond measure: $0.2 \mathrm{~mm}$ in diameter. In a $20 \%$-culture the reduction of the reproductive organs went so far that I could see no trace of them even after nine months. A similar result was observed by BACHMANN ${ }^{1}$ ) in Thamnidium elegans, whose spore-formation was quite suppressed, when cultivated in a strong solution of malt-extract. Schos'TAKowi'sCH ${ }^{2}$ ) also found that Dematium reared in a concentrated solution of cane or grape-sugar produced only sterile mycelium.

d. Potassium nitrate.-In a 5\%-culture white conidia were formed on the 7th day and changed to black after two days more. This early blackening was noticeable also in the case of potassium chloride. The length of conidia-bearing hyphae was $1.7 \mathrm{~mm}$ and the diameter of conidiafruits $0.4 \mathrm{~mm}$. A $15 \%$-culture produced white conidia-fruits on the 9 th day, which blackened on the 14th. A $20 \%$-culture was distinguished by a remarkable diminution of the size of the sexual organs: i.e. conidia-fruits $1.3 \mathrm{~mm}$ thick, conidia-bearing hyphae $1 \mathrm{~mm}$ long.

e. Potassium sulphate.-All cultures prospered well. Both 5\% and 10\%-cultures formed white conidia on the 7 th day, which were tinged dirty brown after five days more. Conidia-fruits $0.8 \mathrm{~mm}$ thick, conidiabearing hyphae $3.8 \mathrm{~mm}$ long.

If we compare the three salts of potassium-chloride, bromide and iodide-we reach the conclusion, that chloride mostly promotes the formation of conidia, next followed bromide and then iodide. As to the colour of conidia-fruits chloride of $5 \%$ or stronger causes the blackening, while bromide and iodide let it remain dirty brown through all cultures.

1) J. Bachmann. loc. cit. S. 129.

2) W. Scrostakowitsch. Ueber die Bedingungen der Conidienbildung bei Russthanpilzen. Flora. 1895. Bd. LXXXI. S. 393. 


\section{Sodium salts.}

Control-culture.-On the 4th day after sowing white conidia were formed, which became yellow on the 5th and dirty brown on the 7th. The other details were quite the same as in the case of potassium salts.

a. Sodium chloride. ${ }^{1}$ ) - A $5 \%$-culture produced white conidia on the 6th, which were tinged dirty brown on the 13th and blackened on the 18th. In 10\% conidia were white on the 7 th, yellow on the 13th, dirty brown on the 18th and black thereafter. 15\% after a month formed short-stalked conidia-fruits, which never densely developed. In these cultures, as the concentration of the medium ascended the reproductive organs diminished in size: so conidia-fruits and conidia-bearing hyphae were in $5 \% 0.7 \mathrm{~mm}$ thick and $2.5 \mathrm{~mm}$ long respectively, while in $15 \% 0.4 \mathrm{~mm}$ thick and $1.2 \mathrm{~mm}$ long respectively. Moreover a remarkable thickening of the cell-wall of conidia-bearing hyphae characterized the cultures of this salt.

b. Sodium bromide. - The general fates of 5-20\%-cultures were nearly the same as those of the corresponding potassium salt.

c. Sodium iodide.-A 5\%-culture showed a slow development of conidia-fruits, which were long-stalked and of various sizes, as we saw in the case of the potassium salt. The other cultures are now in the course of experiment.

d. Sodium nitrate-5-20\%-cultures were experimented with. The mode of reduction of conidia-fruits in the media of stronger concentration was similar to that of potassium nitrate.

\section{Ammonium salts.}

Control-culture.-As above.

a. Ammonium chloride.-A 5\%-culture formed white conidia on the 5th day after sowing, the greater part of which changed to dirty brown, and the rest to black on the 7th. Ripened conidia-fruits were larger, giving a diameter of $0.7 \mathrm{~mm}$. Conidia in a $10 \%$-culture were white on the 7 th, brown and black on the 15th. Conidia-bearing hyphae were much shortened-1.8 mm.

b. Ammonium bromide.-5-20\%-cultures showed the usual phenomena. Nothing particular could be observed.

1) As our fundamental medium solution contained $3.6 \%$ of this salt we must here, for strict measurement, add 3.6 to the percentage number of each culture. 
c. Ammonium nitrate.-5-25\%-cultures were examined. The results were as ustal.

\section{Magnesium salts.}

Control-culture.-As above.

a. Magnesium chloride. - 5-20\%-cultures were observed. Early blackening \&c. were similar to the cases of the other chlorides. Only it had somewhat a weaker action upon my fungus, when compared with that of potassium or sodium.

b. Magnesium sulphate.-A 5\%-culture formed white conidia on the 4th day after inoculation, which coloured dirty brown on the 7th. Conidia-fruits $0.7 \mathrm{~mm}$ thick. In $10 \%$ conidia were white on the 4 th, yellow on the 6th and black on the 7 th ; those of $20 \%$ white on the 5th, black on the 7th. A 30\%-culture was characterized by a great diminution of the size of reproductive organs: i.e. conidia-fruits $0.25 \mathrm{~mm}$ in diameter, conidiabearing hyphae $1.6 \mathrm{~mm}$ in length and $13 \mu$ in thickness, with the cell-wall of $2 \mu$ thick. This culture produced white conidia on the 6th day, which changed to black first on the 12th. The tendency of spore-blackening with increase of concentration was an interesting phenomenon.

\section{Conclusions.}

1. As the concentration of the liquid-medium increases the conidiaformation of Aspergillus niger is retarded.

2. When the concentration of the medium ascends the conidia-fruits are found to decrease in size.

3. The stronger the concentration of the medium-solution becomes the shorter are the conidia-bearing hyphae.

4. With the concentration of the medium the blackening of conidia is much promoter.

5. In the solutions of strong concentration the conidia-formation is entirely suppressed.

Sendai, June 10, 1899. 